\title{
Penerapan Model Waterfall Pada Perancangan Program Pemesanan Percetakan Berbasis Desktop
}

\author{
Hendri $^{1}$, Melan Susanti ${ }^{2}$ \\ ${ }^{1,2}$ STMIK Nusa Mandiri, \\ e-mail: ${ }^{1}$ hendri.hed@ nusamandiri.ac.id, ${ }^{2}$ melan.msu@nusamandiri.ac.id
}

\begin{tabular}{ccc}
\hline Diterima & Direvisi & Disetujui \\
$03-03-2020$ & $05-05-2020$ & $20-05-2020$ \\
\hline
\end{tabular}

\begin{abstract}
Abstrak - Berkah Abadi adalah jasa percetakan yang terus berkembang yang menerima berbagai jenis pemesanan cetakan. Hal ini akan menjadi sebuah masalah ketika pengelolaan data pemesanan hingga pembayaran masih bersifat manual sehingga banyak masalah yang dihadapi pemilik Berkah Abadi diantaranya proses data pemesanan masih dicatat dalam buku, proses tanda terima pemesanan masih menggunakan nota pembayaran, lalu nota pembayaran tersebut hanya disimpan dan menumpuk dengan nota pembayaran lainnya, yang apabila ingin diperlukan lagi maka sulit untuk mencarinya karena harus dicari satu persatu dan begitu pula dengan proses pembuatan laporan yang dimana hanya melihat catatan yang ada pada aplikasi Microsoft Excel. Pada perancangan program pemesanan hingga pembayaran percetakan maka penulis menggunakan pengumpulan data yaitu metode pengembangan perangkat lunak dengan menggunakan model waterfall seperti analisis kebutuhan perangkat lunak, desain, pembuatan kode program, penguji. penulis menggunakan teknik pengumpulan data yaitu observasi, wawancara serta studi pustaka. Dengan adanya penelitian ini usaha jasa percetakan Berkah Abadi dapat mengurangi resiko kesalahan yang dapat di timbulkan dari proses yang masih manual yang disebabkan oleh kesalahan manusia, Memberikan pemesanan hingga pembayaran yang lebih cepat tanpa mengurangi keakuratan informasi yang dihasilkan, kemudahan untuk penelusuran dan pencarian data dan memudahkan dalam pembuatan laporan.
\end{abstract}

Kata Kunci: Program, Pemesanan, Waterfall.

\begin{abstract}
Abstrak - Berkah Abadi is a growing printing service that accepts various types of printed orders. This will become a problem when the management of order data until payment is still manual, so many problems faced by the owner of Berkah Abadi include the ordering data process is still recorded in the book, the order receipt process still uses a payment note, then the payment note is only stored and piled up with other payment memorandum, which if you want to be needed again it is difficult to look for it because it must be searched one by one and so is the process of making reports which only see the notes in the Microsoft Excel application. In designing the ordering program to printing payment, the writer uses data collection, namely software development methods using the waterfall model such as software requirements analysis, design, program code creation, testers. The author uses data collection techniques namely observation, interviews and literature study. With this research, Berkah Abadi's printing service business can reduce the risk of errors that can be generated from processes that are still manual caused by human error, give orders to faster payments without reducing the accuracy of the information generated, easy to search and search data and facilitate in making reports.
\end{abstract}

Keywords: Program, Ordering, Waterfall.

\section{PENDAHULUAN}

Menurut (Sukrianto \& Agustina, 2018)“Sistem Informasi telah menjadi suatu kebutuhan yang mendesak di berbagai bidang kehidupan termasuk bidang bisnis.Informasi merupakan hasil pengolahan data yang sebelumnya dikumpulkan dan mendukung satu sama lain dan dapat menjadi informasi yang memiliki kegunaan bagi siapapun yang menerimanya". Oleh karena itu sebagian besar organisasi bisnis telah menjadikan sistem informasi sebagai yang penting bagi kelangsungan bisnisnya. Namun sebagian lagi masih belum menggunakan sistem informasi secara optimal. Salah satunya organisasi bisnis yang belum menggunakan sistem informasi secara optimal adalah Berkah Abadi.

Berkah Abadi adalah usaha jasa percetakan yang terus berkembang yang menerima berbagai jenis pemesanan cetakan. Menurut (Martono et al., 2017) "Pengertian pesan adalah suruhan (perintah, nasehat, permintaan, amanat) yang harus dilakukan atau disampaikan kepada orang lain". Hal ini akan menjadi sebuah masalah ketika pengelolaan data pemesanan hingga pembayaran masih bersifat manual sehingga banyak masalah yang dihadapi pemilik Berkah Abadi diantaranya proses data pemesanan masih dicatat dalam buku, proses tanda terima pemesanan masih menggunakan nota, lalu 
nota pembayaran tersebut hanya disimpan dan menumpuk dengan nota lainnya, yang apabila ingin diperlukan lagi maka sulit untuk mencarinya karena harus dicari satu persatu dan begitu pula dengan proses pembuatan laporan yang dimana hanya melihat catatan yang ada pada aplikasi Microsoft Excel.

Maka dari itu dibutuhkan suatu pengembangan sistem sehingga sistem informasi pemesanan hingga pembayaran percetakan pada Berkah Abadi menjadi sebuah informasi modern yang terkomputerisasi tersebut diperlukan dalam jangka panjang, guna meningkatkan kualitas informasi yang dihasilkan oleh sistem seperti kecepatan, keakuratan, ketepatan waktu dan dapat memperbaiki kinerja Berkah Abadi menjadi lebih baik. Terutama untuk menanggapi kebutuhan pelanggan akan informasi pemesanan percetakan, dan juga untuk memudahkan Berkah Abadi dalam pembuatan laporan. Melihat permasalahan yang terjadi diatas, penulis merasa tertarik untuk membuat perancangan sebuah program pemesanan dalam penelitian ini, tujuan dari penelitian ini diharapkan akan mendapatkan solusi dari permasalahan tersebut dengan merancang dan membangun suatu program pemesanan percetakan yang mampu meningkatkan kualitas informasi dan kinerja Berkah Abadi menjadi lebih baik dengan metode pengembangan perangkat lunak dengan menggunakan model waterfall.

\section{KAJIAN LITERATUR \\ a. Bahasa Pemrograman}

Menurut (Husnil Kamil, 2016) "Bahasa Pemrograman adalah bahasa buatan yang digunakan untuk mengendalikan perilaku dari sebuah mesin, komputer, sehingga dapat digunakan untuk memberitahu komputer tentang apa yang harus dilakukan“. Di dalam bahasa pemograman ini penulis menggunakan Java Development Kit (JDK) untuk pembuatan program. Menurut (Rachmatika \& Wulandari, 2019) "Java merupakan bahasa yang bersifat multiplatform, bahasa ini dapat digunakan di berbagai platform, dari Windows hingga linux. Java merupakan salah satu bahasa yang popular saat ini. Salah satu alasan lain mengapa Java merupakan bahasa program yang populer yaitu dikarenakan Java dapat berjalan diberbagai platform sistem operasi”.

\section{b. ERD}

Menurut (Haryani, 2015), "ERD (Entity Relationship Diagram) merupakan suatu model yang didesain agar dapat mengidentifikasikan sebuah entitas yang menjelaskan data dan hubungan antar data, yaitu dengan mencantumkan dalam cardinality". Elemen - elemen yang membentuk ERD diantaranya :

1) Entity yaitu entitas misalnya obyek, orang, tempat, , atau kejadian yang penting bagi perusahaan, sehingga segala atributnya harus disimpan dalam basis data.

2) Attribute. Setiap entitas yang berkarakterisik tertentu yang dinamakan dengan atribut. Contoh dari attribute adalah Employee Name, Customer Name, Employee ID dan Customer ID.

3) Identifier merupakan attribute yang memiliki kegunaan untuk mengidentifikasi entity. Tiga jenis pengenal, yaitu Primary Key, Foreign Key, Secondary Key.

4) Relationship merupakan jalinan antara entitas.

5) Cardinality merupakan Masalah yang terjadi dalam hubungan antar entitas.

\section{c. LRS}

Menurut (Sukmaindrayana \& Sidik, 2017), "LRS (Logical Record Structure) merupakan hasil presentasi ulang dari struktur record pada tabel-tabel yang terbentuk dari hasil antar kumpulan entitas.”. Dalam pembuatan LRS terdapat tiga hal yang dapat mempengaruhi, yaitu:

1) Jika tingkat hubungan (cardinality) satu pada satu (one-to-one), maka digabungkan dengan entitas yang lebih kuat (strong entity), atau digabungkan dengan entitas yang memiliki atribut yang lebih sedikit.

2) Jika tingkat hubungan (cardinality) satu pada banyak (one-to-many), maka hubungan relasi atau digabungkan dengan entitas yang tingkat hubungannya banyak.

3) Jika tingkat hubungan (cardinality) banyak pada banyak (many-to-many), maka hubungan relasi tidak akan digabungkan dengan entitas manapun, melainkan menjadi sebuah LRS.

\section{METODE PENELITIAN}

Suatu cara yang dipakai dalam mengembangkan perangkat lunak ini menggunakan model "waterfall". Menurut (Maulana, 2019) metode air terjun adalah tempat analis dan pengguna berpindah dari satu tahap ke tahap berikutnya. Metodologi pengembangan waterfall memiliki keuntungan mengidentifikasi requirement jauh sebelum pemrograman dimulai dan membatasi perubahan requirement sebagai hasil proyek. Kelemahan utama waterfall adalah bahwa desain harus benar-benar ditentukan sebelum program dimulai, diperlukan waktu yang lama antara selesainya usulan sistem dalam tahap analisis dan penyerahan sistem, dan pengujian diolah hampir menjadi ketinggalan jaman dalam tahap implementasi.

Model waterfall memberikan pendekatan siklus hidup perangkat lunak berurutan atau berurutan mulai dari tahap analisis, desain, pengkodean, pengujian, dan dukungan.

a. Analisa 
Persyaratan perangkat lunak berkonsentrasi pada proses pengumpulan persyaratan untuk menentukan persyaratan perangkat lunak sehingga perangkat lunak dapat dipahami sebagai kebutuhan pengguna. Spesifikasi persyaratan perangkat lunak pada tahap ini perlu didokumentasikan.

b. Desain

Rancangan perangkat lunak adalah proses multilayer, yang berfokus pada desain pemrograman perangkat lunak, termasuk struktur data, arsitektur perangkat lunak, representasi antarmuka, dan proses pengkodean. Tahap ini mengubah persyaratan perangkat lunak dari tahap analisis persyaratan ke representasi desain sehingga dapat diimplementasikan sebagai program pada tahap selanjutnya. Rancangan perangkat lunak yang diperoleh pada tahap ini juga perlu disimpan.

c. Pembuatan Kode Program

Desain harus dikonversi menjadi program perangkat lunak.

d. Pengujian

Fokus dari tes ini adalah logika dan fungsi dari perangkat lunak, dan memastikan bahwa semua bagian telah lulus tes untuk meminimalkan kesalahan (kesalahan) dan memastikan bahwa hasil keluaran memenuhi persyaratan. Menurut (Taufiq dan Ermawati, 2017) "pengujian black box (pengujian black box), yaitu pengujian perangkat lunak dalam hal spesifikasi fungsional tanpa pengujian desain dan kode program".

e. Pendukung (support) atau Pemeliharaan (maintenance)

Kemungkinan mengubah pengalaman setelah mengirim pengalaman perangkat lunak kepada pengguna tidak dikesampingkan. Karena kesalahan yang terjadi dan tidak ada kesalahan yang terdeteksi selama pengujian, perubahan dapat terjadi atau perangkat lunak harus beradaptasi dengan lingkungan baru.

\section{HASIL DAN PEMBAHASAN}

Menurut (Maulana, 2019)“ Metode yang digunakan pada pengembangan perangkat lunak ini menggunakan metode waterfall yang terbagi menjadi lima tahapan yaitu:

1. Analisis Kebutuhan Perangkat Lunak

Penulis melakukan pengamatan secara langsung untuk menganalisa kebutuhan sistem informasi yang sedang berjalan pada Berkah Abadi. Analisa ini dilakukan agar sistem yang dirancang bisa sesuai dengan kebutuhan, dilakukan dengan mengidentifikasi kebutuhan pengguna yang terdiri dari administrasi dan kasir, serta kebutuhan sistem dalam pembuatan program yang sesuai dengan sistem pada Berkah Abadi.

2. Desain

Dalam tahap pembuatan desain, penulis merancang terlebih dahulu desain untuk tampilan dan alur kerja program yang akan dibuat. Penulis menggunakan ERD (Entity Relationship Diagram), LRS (Logical Record Sturcture), HIPO (Hierarchy Input Process Output), spesifikasi file, spesifikasi program, spesifikasi rancangan masukan, spesifikasi rancangan, keluaran, dan flowchart, sebelum melakukan pembuatan kode program.

3. Pembutan Kode Program

Pada tahap ini, Penulis mentranslasikan desain ke dalam program perangkat lunak berupa kode program menggunakan Java Development Kit (JDK) 1.6 dengan melakukan coding.

4. Pengujian black-box testing

Pada tahap pengujian, penulis melakukan serangkaian pengujian terhadap program menggunakan metode black-box testing untuk memastikan bahwa perangkat lunak yang dibangun sudah bekerja dengan baik dari segi fungsionalitas.

5. Pendukung atau pemeliharaan

Tahap ini, dilakukan pemeliharaan terhadap hardware maupun software dengan melakukan backup database serta melakukan pengembangan program melalui referensi yang ada sehingga permasalahan yang terjadi manjadi program yang terbarukan dan selalu mengikuti perkembangan usaha kedepannya".

\section{a. Entity Relationship Diagram (ERD)}

Menurut (Haryani, 2015) Entity Relationship Diagram (ERD) adalah komponen-komponen himpunan entitas dan himpunan relasi yang masingmasing dilengkapi dengan atribut-atribut yang mempresentasikan seluruh fakta di dunia nyata". 


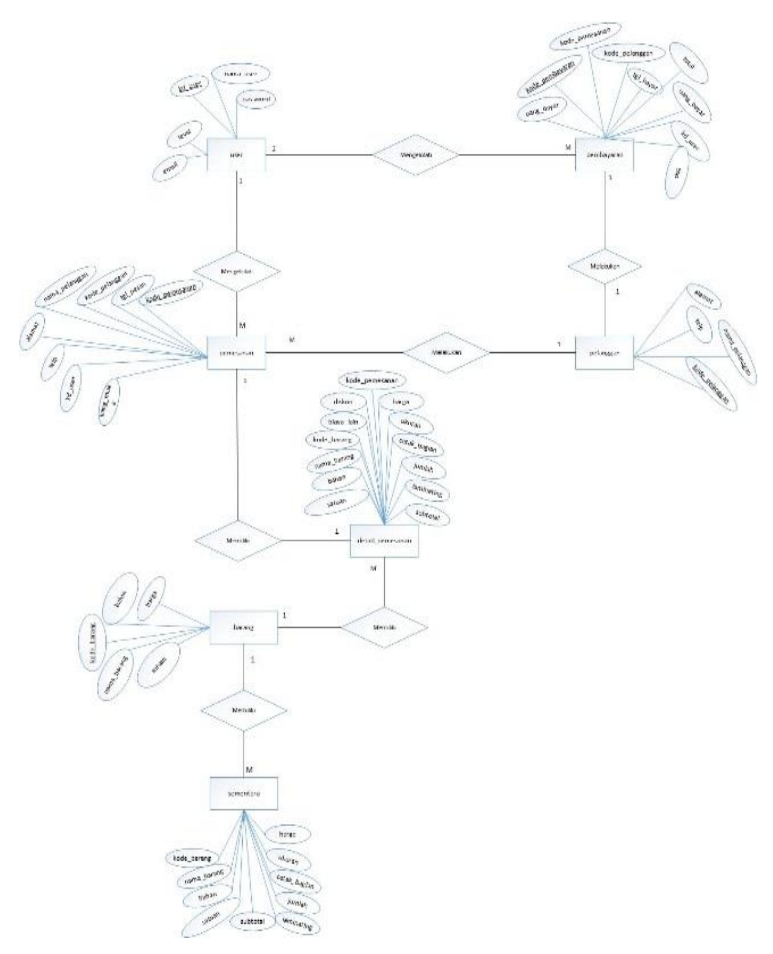

Sumber : penelitian 2019

\section{Gambar 1. Entity Relationship Diagram}

\section{b. Logical Record Structured (LRS)}

Menurut (Firmansyah \& Udi, 2017) "Sebelum tabel dibentuk dari field atau atribut entitas secara fisik atau level internal, maka harus dibuatkan suatu bentuk relational model yang dibuat secara logic atau level external dan konsep, dari pernyataan tersebut dibutuhkan yang disebut dengan Logical Record Structure (LRS)".

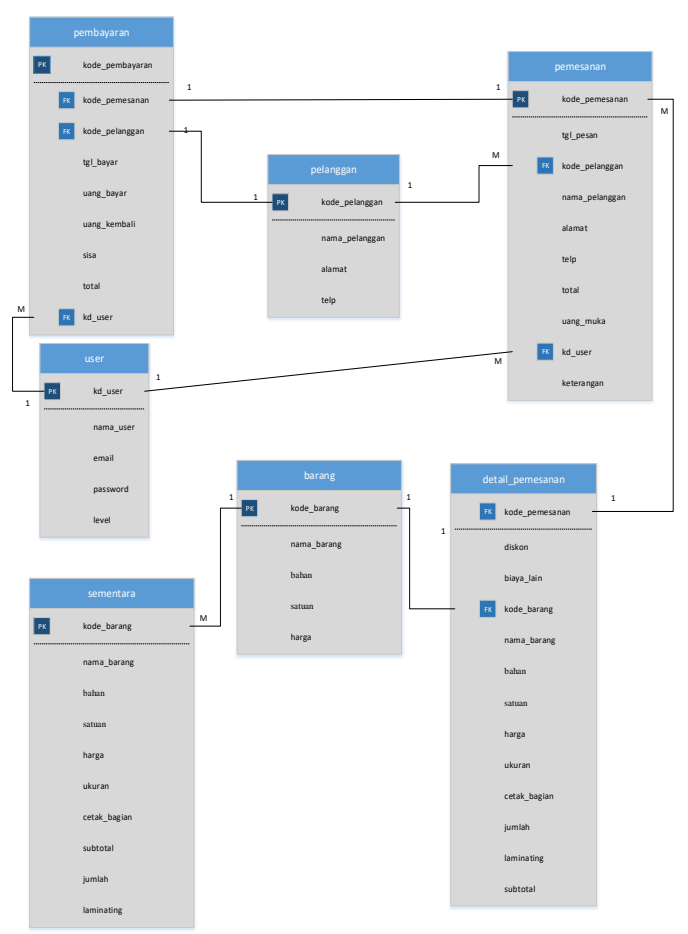

Sumber : penelitian 2019

\section{Gambar 2. LRS Sistem Informasi}

\section{c. HIPO ( Hierarky Input Proses Output )}

HIPO ( Hierarky Input Proses Output ), merupakan metodologi yang dikembangkan dan didukung oleh IBM. Menurut (Taufiq dan Ermawati, 2017) "HIPO sebenarnya adalah alat dokumentasi program. HIPO digunakan sebagai alat desain dan teknik dokumentasi dalam siklus perkembangan sistem.

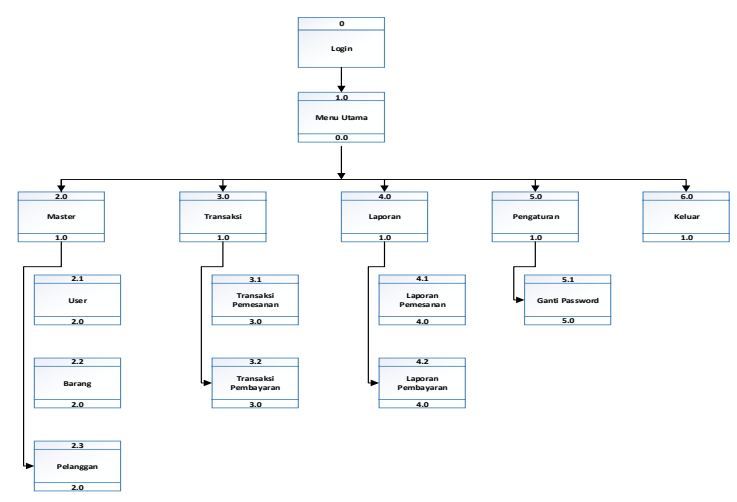

Sumber : penelitian 2019

\section{Gambar 3.}

HIPO (Hierarchy Input Proses Output) 


\section{d. Flowcart}

Flowchart merupakan model untuk mempresentasikan pengelolahan data informasi dan dokumen yang terjadi pada suatu proses dalam (Agustiani, 2019)

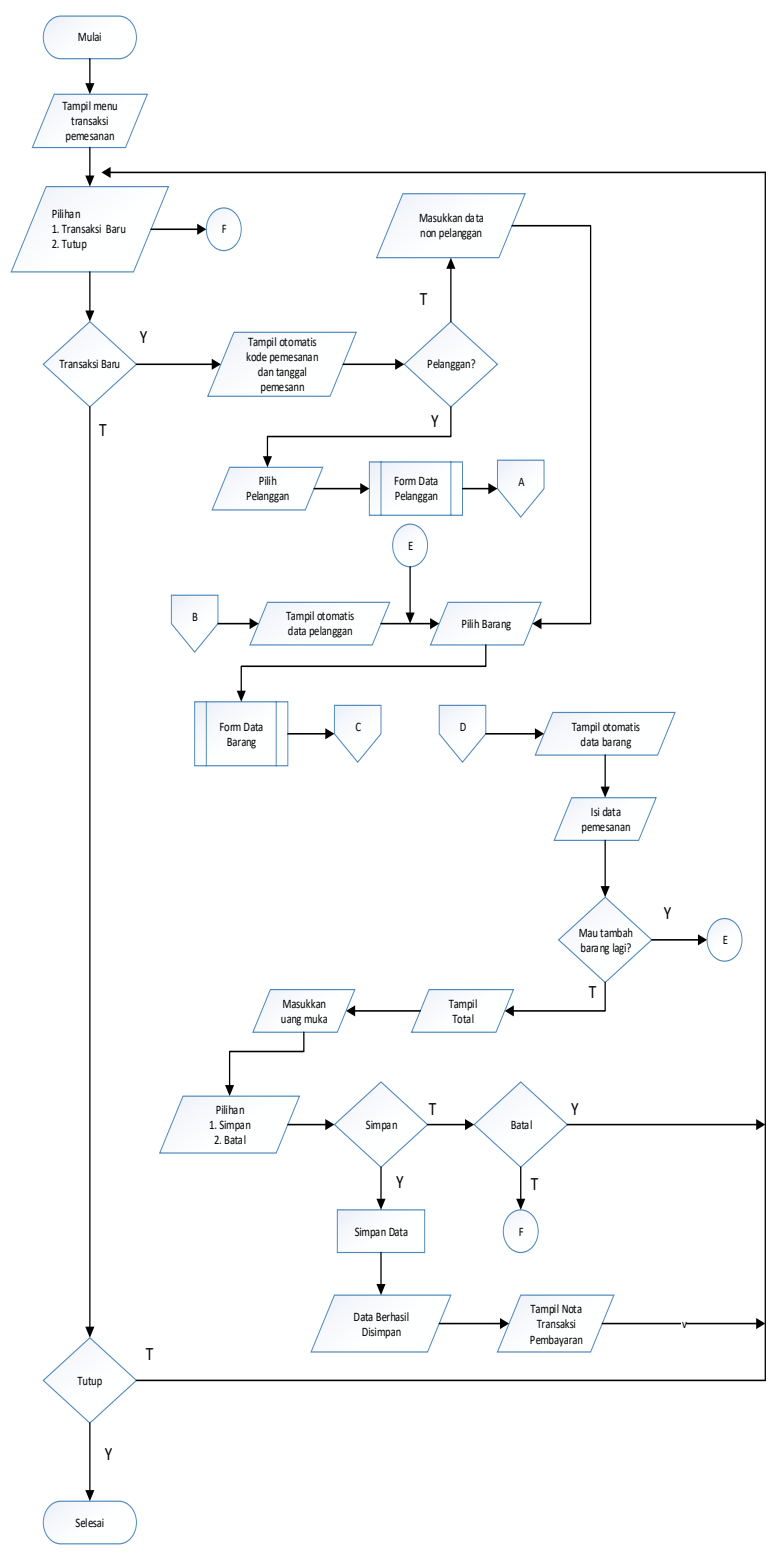

Sumber : penelitian 2019

Gambar 4.

Flowchart Transaksi Pemesanan

\section{e. Implementasi Rancangan Antar Muka}

Form Transaksi Pemesanan

From transaksi untuk melakukan pencatatan pelayanan pemesanan percetakan

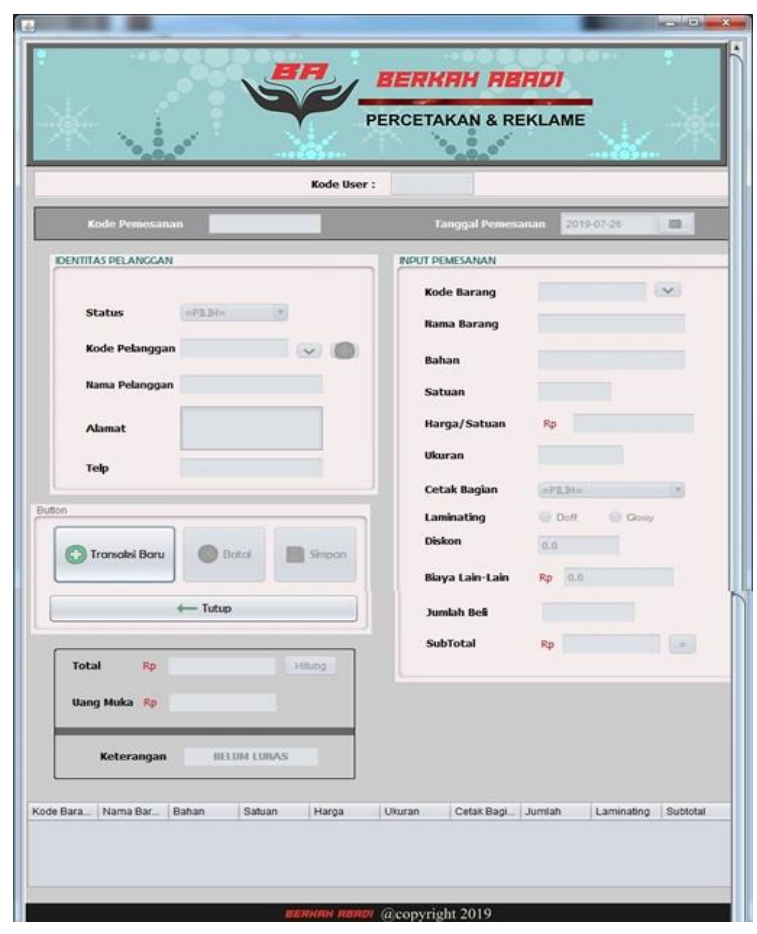

Sumber : penelitian 2019

\section{Gambar 5.}

\section{Form Transaksi Pemesanan}

From transaksi pembayaran

From transaksi pembayaran untuk melakukan pembayaran setelah melakukan transaksi pemesanan percetakan 


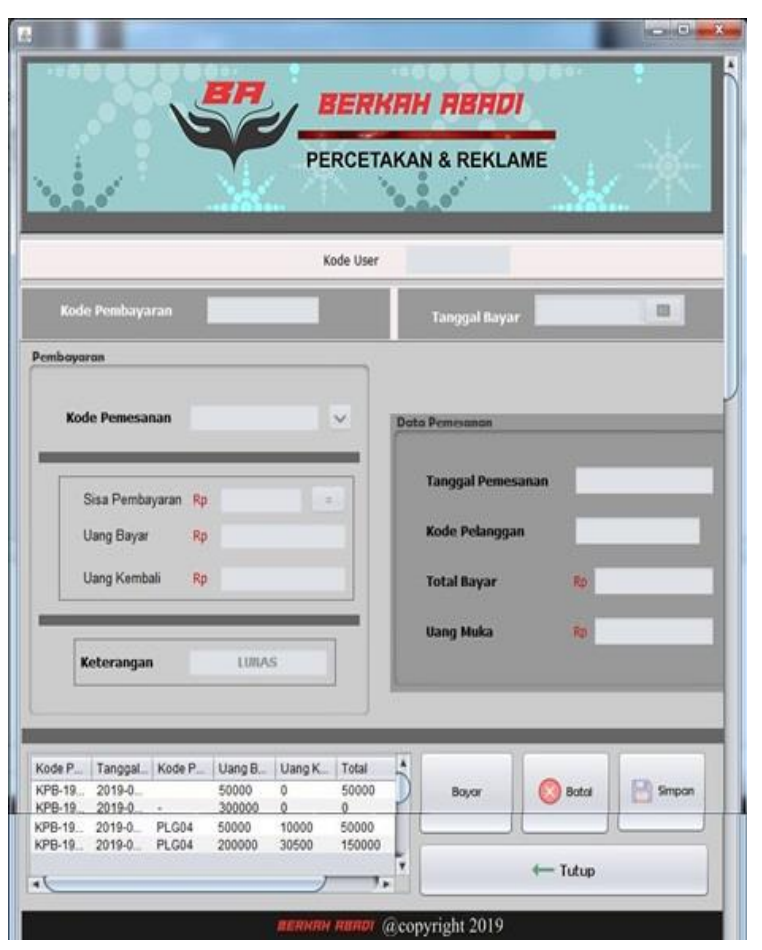

Sumber : penelitian 2019

Gambar 6.

Form Transaksi Pembayaran

Form Laporan Transaksi Pembayaran

Form ini digunakan untuk melihat laporan transaksi pembayaran dan dapat dilakukan sesuai dengan kebutuhan.

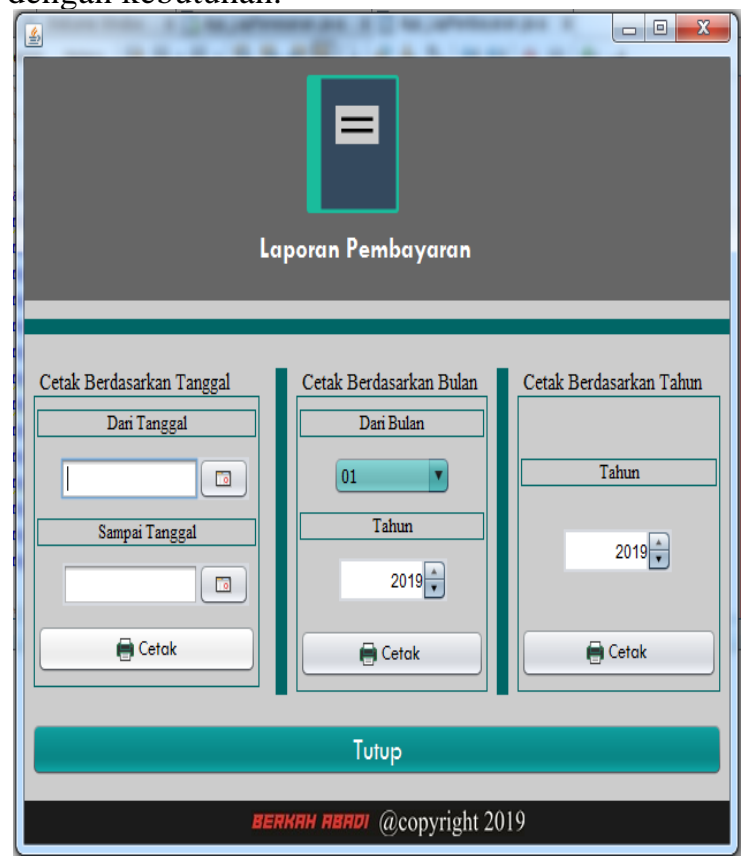

Sumber : penelitian 2019

Gambar 6.

Form Laporan Transaksi Pembayaran

\section{KESIMPULAN}

Program Pemesanan Percetakan Berbasis Desktop dalam penelitian ini dapat Mengurangi resiko kesalahan yang dapat di timbulkan dari proses yang masih manual yang disebabkan oleh kesalahan manusia (human error), Memberikan pemesanan hingga pembayaran yang lebih cepat tanpa mengurangi keakuratan informasi yang dihasilkan, kemudahan untuk penelusuran dan pencarian data atau informasi yang baik bagi pengguna dan pemilik usaha yang dapat dipakai sebagai bahan dalam proses pengambilan kebijakan dan memudahkan dalam pembuatan laporan. Untuk memudahkan Berkah Abadi dalam pembuatan laporan. dan meningkatkan kualitas informasi yang dihasilkan oleh sistem seperti kecepatan, keakuratan, ketepatan waktu sehingga dapat memperbaiki kinerja Berkah Abadi menjadi lebih baik.

Perlu diadakan pelatihan kepada pengguna dan mengantisipasi kesalahan yang mungkin timbul pada program. Perangkat yang digunakan untuk menjalankan program hendaknya sesuai dengan spesifikasi yang dibutuhkan agar program dapat berjalan dengan baik. Penelitian berikutnya sebaiknya dilanjutkan pada tahapan selanjutnya yaitu perbaikan sistem keamanan data agar lebih baik lagi dan penambahan fungsi dari program agar sesuai kebutuhan.

\section{REFERENSI}

Agustiani, D. (2019). Analisis Alur Proses Pengelolaan Linen Kotor Pada Instalasi Laundry di BLUD RS Sekarwangi. Jurnal Manajemen Kesehatan Yayasan RS.Dr. Soetomo, 5(1), 46. https://doi.org/10.29241/jmk.v5i1.131

Firmansyah, Y., \& Udi, U. (2017). Penerapan Metode SDLC Waterfall Dalam Pembuatan Sistem Informasi Akademik Berbasis Web Studi Kasus Pondok Pesantren Al-Habib Sholeh Kabupaten Kubu Raya, Kalimantan Barat. Jurnal Teknologi Dan Manajemen Informatika, https://doi.org/10.26905/jtmi.v4i1.1605

Haryani. (2015). Pemanfaatan Web Sistem Informasi Akademik Sebagai Pengontrol Nilai Siswa (Studi Kasus) Mts Modern Al-Islam Nganjuk. Paradigma, 17(2), 50-58.

Husnil Kamil, A. D. (2016). Pembangunan Sistem Informasi Pelayanan Jasa Laundry Berbasis Web Dengan Fitur Mobile Pada 21 Laundry Padang. Seminar Nasional Sains Dan Teknologi Fakultas Teknik Universitas Muhammadiyah Jakarta, 8(November), 1-9. https://media.neliti.com/media/publications/17 
2316-ID-pembangunan-sistem-informasipelayanan-j.pdf

Martono, A., Solehudin, \& Putra, F. J. E. (2017). Project Application untuk Sistem Pemesanan dan Pengiriman Barang Berbasis Web pada PT. Arai Rubber Seal Indonesia. 3(2), 162170.

https://scholar.google.com/citations?user=fhZr IosAAAAJ\&hl=id\#d=gs_md_cita$\mathrm{d} \& \mathrm{u}=\% 2$ Fcitations\%3Fview_op\%3Dview_cit ation\%26hl\%3Did\%26user\%3DfhZrIosAAA AJ\%26citation_for_view\%3DfhZrIosAAAAJ \%3AqxL8FJ1GzNcC\%26tzom\%3D-420

Maulana, Y. I. (2019). Sistem Informasi Penyedia Layanan Jasa Pengiriman Barang Impor Pada PT Pelita Barat Daya. Jurnal Infortech, 1(2), 35-40.

Rachmatika, R., \& Wulandari, R. D. (2019). RANCANGAN APLIKASI LAUNDRY BERBASIS DEKSTOP PADA KRISNA LAUNDRY UNTUK WILAYAH LIMO DESIGN OF LAUNDRY APPLICATION BASED ON DECSTOP ON KRISNA LAUNDRY FOR LIMO AREAS. 4, 46-53.

Sukmaindrayana, A., \& Sidik, R. (2017). Aplikasi Grosir Pada Toko RSIDIK Bungursari Tasimalaya. Jurnal Manajemen Informatika, 4(2), 1-30. https://doi.org/10.1017/CBO9781107415324.0 04

Sukrianto, D., \& Agustina, S. (2018). Pemanfaatan Sms Gateway Pada Sistem Informasi Absensi Siswa Di Sman 12 Pekanbaru Berbasis Web. Jurnal Intra Tech, 2(2), 78-90. http://www.journal.amikmahaputra.ac.id/index .php/JIT/article/view/31

Taufiq dan Ermawati. (2017). Bestandsübersicht. IJSE - Indonesian Journal on Software Engineering, $\quad 3(2), \quad 1-7$. http://ejournal.bsi.ac.id/ejurnal/index.php/ijse/ article/view/2812/1836 